\title{
Types of Credit Risks and Strategies to Improve Risk Identification by Internet of Intelligences
}

\author{
Chongfu Huang ${ }^{1,2}$ \\ ${ }^{1}$ Academy of Disaster Reduction and Emergency Management, Beijing Normal University, Beijing 100875, China. \\ ${ }^{2}$ Beijing Cazl Technology Service Co., Ltd., Beijing 100088, China \\ E-mail:hchongfu@gmail.com
}

\begin{abstract}
Today, people mainly consider credit risks from view of powerful players. The role of the Internet in the credit risk management is not fully. In this paper, we have a comprehensive look at the credit risks, so that, suggest two concepts: binary credit risk and triad credit risk. The Internet of intelligences is introduced to improve the recognition of credit risk. This paper shows the intensions of three binary credit risks, respectively, as well as overviews the main methods to analyze them. The study shows that, the bank's customer credit risk is a simple credit risk. The indirect feeling strategy in internet of intelligences can improve the recognition of credit risk that would be seriously affected by changes in the political, economic and social environment.
\end{abstract}

Keywords: Credit risk; Customer; Bank; Government; Internet of intelligences

\section{信用风险的种类和用智联网改善风险识别的方略}

\author{
黄崇福 1,2 \\ 北京师范大学减灾与应急管理研究院, 北京 100875 , 中国 \\ 北京崇安智联科技服务有限责任公司，北京 100088，中国
}

\begin{abstract}
摘要: 今天, 人们主要是从强势者的角度看待信用风险, 互联网在信用风险管理中的作用也没有充分发 挥。为此, 本文全面地审视了信用风险, 提出了二元信用风险和三元信用风险的概念, 并提出了用智联网 改善信用风险识别的方略。本文分别阐述了三种二元信用风险的内涵, 概述了主要分析方法。研究表明, 银行的客户信用风险只是一种简单的信用风险。对与政治、经济和社会环境等变化密切相关的信用风险, 智联网的间接感受方略可改善信用风险识别。
\end{abstract}

关键词：信用风险; 客户; 银行; 政府; 智联网

\section{1. 引言}

多数学者谈及信用风险, 主要是从商业银行的 角度评判贷款者的信用度, 进而论及银行承担的风 险。也有专家从政府的角度评判银行的不良贷款余 额, 进而论及金融风险。其实, 有一种与金融相关 的信用风险更为重要, 即: 政府信用风险。如果政 府的金融信用急剧贬值, 民众财富必然大量缩水。 政府信用风险, 等价于恶性通货膨胀风险。显然, 信用风险不仅仅是银行和政府所面临的主要风险, 也是民众不得不关注的重要风险。银行、政府和民 众, 三者之间的信用风险, 无时不刻不在发挥作 用。

现有的信用风险模型, 主要用于商业银行依据 大量法人客户的信息数据, 从统计意义上评估具体
客户违约的可能性。商业银行对非上市公司进行信 用风险度量则更多地是考查其历史违约数据和企业 财务指标。

巴塞尔新资本协议对商业银行承担的信用风 险、市场风险、操作风险等, 做了严格的规定并建 议了一些具体的分析方法。本质上, 巴塞尔协议制 定了以最低资本要求、监管当局的监督检查和市场 纪律为三大支柱的监管框架, 是为了管理银行的信 用风险, 以期有效地控制和管理国家、公司、项 目、零售、机构、股权等六类风险敞口。

主权信用评级, 是评级机构对国家的中央政府 作为债务人履行偿债责任的信用意愿与信用能力的 一种判断。其国内生产总值增长趋势、对外贸易、 
国际收支情况、外汇储备、外债总量及结构、财政 收支、政策实施等, 均影响国家的偿还能力。一旦 该国发行的货币量大大超过其偿还能力, 就发生严 重的政府信用危机。

本文按下述逻辑结构展开研究: 在较全面地审 视了信用风险的本质特征后, 在第 2 节中对信用风 险进行了分类。在第 $3 、 4 、 5$ 节中分别对 3 种二元 信用的内涵和主要分析方法进行了概述。本文在第 6 节中对三元信用的研究方法进行了探讨。在第 7 节中引入了智联网工具, 并提出了用直接识别法和 间接感受法改善信用风险识别的方略。第 8 节总结 了存在 6 类信用风险及智联网能改善信用风险识别 的结论。

\section{2. 信用风险的种类}

本质上, 信用风险是指契约的一方或多方不能 履约而给其他方造成经济损失的风险。现实中, 人 们主要是从强势者的角度看待信用风险。特别地, 借款者违约给银行造成经济损失的风险, 成为了信 用风险的主要研究内容。

事实上, 在一个复杂的社会系统中, 存在着大 大小小的银行, 林林总总的政府部门, 以个体或组 织出现的民众。令 $B, G$ 和 $P$ 分别为银行集合、政 府部门集合和民众集合, 则表征信用风险的基本空 间是 $\Omega=\{B, G, P\}$ 。显然， $\Omega$ 是一个离散点空间。

$\forall X, Y \in \Omega$, 将 $X$ 中的个体 $x$ 承担由于 $Y$ 中的个 体 $y$ 之信用不良产生的信用风险记为

$$
r_{x y}=\varphi_{x}(y)
$$

不失一般性, $\forall X \in \Omega$, 记其容量（元素个数） 为 $n(X)$, 即: $|X|=n(X)$ 。易知, $\forall X, Y \in \Omega$, 其卡氏积 $X \times Y$ 上存在一个信用风险矩阵:

$$
R_{X \times Y}=\left(\begin{array}{cccc}
r_{x_{1} y_{1}} & r_{x_{1} y_{2}} & \cdots & r_{x_{1} y_{n(Y)}} \\
r_{x_{2} y_{1}} & r_{x_{2} y_{2}} & \cdots & r_{x_{1} y_{n(Y)}} \\
\cdots & \cdots & \cdots & \cdots \\
r_{x_{n(X)} y_{1}} & r_{x_{n(X)} y_{2}} & \cdots & r_{x_{n(X)} y_{n(Y)}}
\end{array}\right)
$$

通常, $R_{X \times Y}$ 不是对称矩阵, 即: 如果 $r_{x_{i} y_{j}}, r_{y_{j} x_{i}}$ 不同时为 0 , 则 $r_{x_{i} y_{j}} \neq r_{y_{j} x_{i}}, i=1,2, \ldots, n(X) ; j=1,2, \ldots$, $n(Y)$ 。大部分信用风险的研究工作, 都在于认识 $\varphi_{x}(y)$ 的内涵, 并尽可能建立数学模型, 根据 $y$ 的属 性资料, 计算出 $\varphi_{x}(y)$ 的数值。

事实上, 在一个开放的政治、经济系统中, $\varphi_{x}(y)$ 常常会受来自基本空间 $\Omega$ 中另一元素中的个 体影响。例如, 银行承担房贷者的信用风险, 可能 由于政府就业政策的改变而改变。 $\forall X, Y, Z \in \Omega$, 将 $X$ 中的个体 $x$ 承担由于 $Y$ 和 $Z$ 中的个体 $y, z$ 之信用不良产生的信用风险记为

$$
r_{x y x}=\varphi_{x}(y, z)
$$

称 $R_{X \times Y \times Z}=\left(r_{x y z}\right)_{n(X) \times n(Y) \times n(Z)}$ 为一个三维信用风险矩 阵。显然, 认识 $\varphi_{x}(y, z)$ 的内涵, 并能计算其值, 则 更有利于进行信用风险管理。

由基本空间 $\Omega$ 的构成和式（1）可知, 二元的信 用风险可分为 3 类:

I. 客户信用风险：当 $X=B, Y=P$ 时, 我们称 $\varphi_{x}(y)$ 为客户信用风险。

II. 银行信用风险: 当 $X=G, Y=B$ 时, 我们 称 $\varphi_{x}(y)$ 为银行信用风险。

III. 政府信用风险: 当 $X=P, Y=G$ 时, 我们 称 $\varphi_{x}(y)$ 为政府信用风险。

由式（3）知, 在 $\Omega$ 上还存在 3 类三元信用风 险, 它们分别为:

IV. 民众承担的信用风险, 即: $X=P, Y=G$, $Z=B$ 时的 $\varphi_{x}(y, z)$ 。

V. 银行承担的信用风险, 即: $X=B, Y=P$, $Z=G$ 时的 $\varphi_{x}(y, z)$ 。

VI. 政府承担的信用风险, 即: $X=G, Y=B$, $Z=P$ 时的 $\varphi_{x}(y, z)$ 。

在基本空间 $\Omega=\{B, G, P\}$ 中，民众集合 $P$ 的容 量虽大, 但个体的影响较小, 由其产生的信用风险 最容易被管理。银行集合 $B$ 的容量不大, 但影响远 远超过 $P$ 中的个体, 由其产生的信用风险, 不可小 觑。政府部门集合 $G$ 的容量很小, 但影响巨大, 一 旦失控, 信用体系很可能崩溃。

三元信用风险常常有传递和反馈作用, 评价和 管理并非易事。

\section{3. 客户信用风险的内涵和分析方法}

虽然随着信用方式的不断变化、信用工具的不 断创新, 商业银行对法人客户信用风险本质的认识 也在不断加深, 对客户信用风险的理解也在不断深 化, 但内涵依然是稳定的。这里的客户, 是指银行 的放贷对象, 即: 借款人。通过大量文献的总结, 我们给出下述定义:

定义 1: 借款人不能按期还本付息而给贷款人 造成损失的风险称为客户信用风险。

具有贷款业务的非银行机构, 是一种广义的银 行。因此, 一个合法的贷款人, 是基本空间 $\Omega=\{B, G, P\}$ 中银行集合 $B$ 中的一元。

由于损失只有当违约实际发生时才会产生, 因 此信用风险也称为违约风险。 
目前, 客户信用风险的研究正处在百家争鸣、 百花齐放的阶段。基于不同数据来源, 很多学者采 用不同技术原理开展了大量的、多角度的实证模型 研究。其中, 数理统计方法 (包括多元判别技术、 Logit 模型、主成分分析等) 、资产组合原理结构模 型、数据深度拟合技术和层次分析法等较为常见。

统计方法常用于提炼出信用风险的主要标识及 风险要素、风险内核等, 从而使人们能对标度风险 的量化要素进行分析研究 ${ }^{1}$ 。

客户信用风险分析使用的数据信息主要来自于 所研究商业银行的内部信贷管理系统, 即: 海量的 法人客户信息数据、内部管理的风险信息数据、辅 助判断的参数指标信息、银行内部风险计量参数等 等。其中, 客户的基本信息、财务报表、信用等 级、贷款数量、所属类别（行业、地区等）、银行 管理要件、历史数据等是最重要的信息。

同样的数据, 使用不同形式的模型, 就会得出 不同的客户信用风险。例如, 多元判别、Logit 模 型、主成分分析、结构模型、简约模型、混合模型 等, 常常结果不同, 为此, 人们用有效性检验来判 别模型的适用性。“回判准确率” 是最常用的检验 指标。

值得注意的是, 大多数客户信用风险分析是间 接分析法, 并不能计算出客户信用风险值（期望损 失）。

例如, 由于陷入财务困境的公司其财务比率和 正常公司的财务比率显著不同, 从而人们认为企业 的财务比率能够反应企业信用风险状况, 所以用财 务比率作为风险指标。例如, 早在 1968 年 Altman 就提出了所谓的 “ $Z$ ” 财务比率模型 ${ }^{2}$ :

$Z=0.012 X_{1}+0.014 X_{2}+0.033 X_{3}+0.006 X_{4}+0.999 X_{5}$

式中的 5 个变量分别是 $X_{1}=$ 营运资金/资产总额, $X_{2}$ =留存收益/资产总额, $X_{3}=$ 息税前利润/资产总额,

$X_{4}=$ 股东的收益资产/负债总额, $X_{5}=$ 销售额/资产总 额。通过用破产企业和非破产企业各 33 家共 66 个 样本回归统计出式 (4), 再进行回判比较, 可以判 定, 当 $\mathrm{Z}<1.81$ 时, 企业具有很高的破产几率; 当 $1.81 \leqslant Z<2.675$ 时, 企业处于财务状况不确定之列, 即处于 “灰色地带” ; 当 $Z \geqslant 2.675$ 时, 企业属于正 常企业之列。

\section{4. 银行信用风险的内涵和分析方法}

随着各国金融监管当局对系统性风险的日趋重 视, 银行信用风险成为了人们的关注点之一。

对于风险控制管理来说, 除了要考虑正常情况下 金融机构的可能损失, 更重要的是必须确保在极端市 场情况下, 金融机构所持有的金融资产部分不会让该 机构出现破产的风险。1997 年亚洲金融危机爆发
前, 风险价值(VaR)法广泛用于测量银行的风险。之 后, 人们认为远远不够, 还须考虑市场风险和操作 风险等。巴赛尔委员会提出了压力测试, 找出金融 机构在极端市场情况下的承受能力, 对风险作出判 断。

显然, 相对于客户信用风险而言, 人们对银行 信用风险的研究, 仍处于起步阶段。由于银行的破 产将导致许多社会问题, 并且要由政府来承担, 尽 管最后是用纳税人的钱来收拾烂摊子。因此, 政府 将承担由于银行之信用不良产生的信用风险。据 此, 本文给出下述定义:

定义 2: 银行因管理不善而失去信用给政府造 成损失的风险称为银行信用风险。

投资银行为了追求高额回报, 致使金融衍生产 品不断泛滥, 银行信用风险严重时将导致金融危 机。例如, 美国的两大房贷融资机构房利美和房地 美, 向还贷能力不高的低收入者发放大量按揭贷 款, 再通过资产证券化等手段将这些高风险资产包 装上市, 用此金融衍生产品转移风险牟取暴利, 最 终于 2008 年陷入危局, 并至使雷曼兄弟公司破产, 形成的金融风暴席卷全球。

今天, 全球资本主义所向披靡, 流动性泛滥, 很难监管的大量影子银行呼风唤雨, 其信用风险, 远远超过正规银行。

除了一些正规不正规的金融机构涉足银行业务 成为影子银行外, 银行的表外业务风生水起, 也是 影子银行。

由中国的地方政府发起设立，通过划拨土地、 股权、规费、国债等资产, 迅速包装出一个资产和 现金流均可达融资标准的公司, 虽然被称为 “地方 融资平台”, 其实是一种新型的影子银行。官方的 报导是, 截至 2012 年 9 月末, 平台贷款的余额为 9.25 万亿元, 地方融资平台目前的风险整体可控 ${ }^{3}$ 。 民间研究资料则表明 ${ }^{4}$, 早在 2010 年, 地方政府投 融资平台的贷款余额, 相比 2009 年的 6 万亿增长了 $42 \%$ （达 8.52 万亿）。2010 年末地方政府投融资平 台的银行贷款余额是 GDP 的 20\%, 相当于全国财政 收入的 102\%, 地方财政收入的 209\%。显然, 这种 庞然大物似的影子银行, 其信用风险, 几乎让人不 敢谈及。

由风险价值、市场风险和操作风险为主产生的 银行信用风险, 很难全面系统地进行分析。仅以操 作风险为例, 涉及不完善或有问题的内部程序、人 员及系统或外部事件所造成损失的风险 ${ }^{5}$ 。虽然新巴 塞尔资本协议给出了从简单到复杂的三种方法, 即 基本指标法、标准法和高级计量法, 但目前仍缺乏 成熟的数量模型来度量操作风险。新巴塞尔协议 ${ }^{6}$ 推 
荐使用的高级计量法就有多种模型, 式(5)是其中的 一个模型。

$$
O R=\sum_{i, j} \gamma(i, j) \times E I(i, j) \times P E(i, j) \times L G E(i, j)
$$

式中, $i$ 为第 $i$ 种操作; $j$ 为第 $j$ 类风险事件; $\gamma$ 为预期损 失转化成资本配置要求的转换因子; $E I$ 为风险暴露 的规模和金额; $P E$ 为损失事件的发生概率; $L G E$ 为 事件的损失程度。

\section{5. 政府信用风险的内涵和分析方法}

2012 年 5 月, 高额财政赤字的希腊全面暴发政 府债务危机, 人纷纷到银行去提领存款, 银行出现 严重的挤兄。随后, 一轮又一轮的罢工活动, 使经 济发展雪上加霜。值得宽慰的是, 作为欧元区国家 的希腊, 没有了自主发钞权, 政府不得不采取紧缩 措施, EU 和 IMF 的救援, 基本稳住了势态。

与之形成鲜明对比的是, 西方从 2002 年开始对 津巴布韦实施经济制裁, 并不断加强。这导致津巴 布韦的经济每况愈下, 通货膨胀失控, 100 万亿元 面值的大钞于 2008 年问世, 通胀率超过百分之两 亿。

建立在经济发展和财政收入基础上的政府信 用, 通常都较为坚实。但是, 内因和外因都有可能 削弱或破坏这种信用, 其严重问题给人民造成的风 险, 常常难以承担。据此, 本文给出下述定义:

定义 3: 政府因重大失误导致经济或财政问题 而失去信用给民众造成损失的风险称为政府信用风 险。

显然, 因被动卷入战争或极端自然灾害而使人 民承受苦难, 不属于政府信用风险问题。而以全球 经济危机为借口维持重大失误致使人民承受苦难, 则属于政府信用风险问题。

衡量政府信用风险的两大指标分别是主权信用 评级和通货膨胀率。

主权信用评级, 是信用评级机构对一国政府作 为债务人履行偿债责任的信用意愿与信用能力进行 的评判。惠誉评级、标准普尔和穆迪是国际三大评 级机构。除了要对一个国家国内生产总值增长趋 势、对外贸易、国际收支情况、外汇储备、外债总 量及结构、财政收支、政策实施等影响国家偿还能 力的因素进行分析外, 主权信用评级还要对种种改 革所造成的财政负担进行分析。主权信用评级一般 从高到低, 分为 $\mathrm{AAA}, \mathrm{AA}, \mathrm{A}, \mathrm{BBB}, \mathrm{BB}, \mathrm{B}$, CCC, CC, C。

目前并不存在一个定量模型可以对政府信用风 险进行分析, 这是因为根据定量因素所确定的纯模 型化的方法不能够掌握政治、经济、金融和社会因 素之间相互关系的复杂性, 这些因素之间的关系是
很难预测。穆迪采取了分步骤评级的方法, 共分为 三大步骤、四大因素。

虽然主权信用评级是对国家的信用进行严格评 级, 但聚焦于 “来自某个特定国家的债务人能否得 到他们需要的外汇以便偿付它们未来的外币债务”

7。因此, 充足的外汇储备能使国家获得很高的主权 信用评级。但是, 能对国外履行还款义务并不意味 着本国民众要承担的政府信用风险就小。例如, 本 币对外明显升值而对内严重贬值, 意味着政府的信 用风险正在增加。通货膨胀率, 正好能补充主权信 用评级的不足。

传统的通货膨胀, 指在纸币流通条件下, 因货 币供给过大, 导致货币贬值而引起的一段时间内物 价持续而普遍地上涨现象。今天, 由于电子货币的 出现和授信方式的多样化, 通货膨胀率常常反映在 消费者物价指数 CPI上。CPI由市场上的货物价格增 长百分比来定义。在正常经济体中, 人们的平均工 资增长速度很难超越 $3-4 \%$, 因此大多数国家都将 CPI 超过 $3 \%$ 视为严重的信号。

CPI是一个滞后性的数据, 用其分析政府信用风 险, 并不理想。加之某些国家为了社会的稳定, 刻 意将价格上涨严重的商品排除在CPI成分之外或根据 需要调整各部分比重。用这种人为CPI分析出的结 果, 更是没有意义。在美国, 构成CPI的主要商品共 分八大类, 其中包括: 食品、酒和饮品、住宅、衣 着、教育和通讯、交通、医药健康、娱乐、其他商 品及服务, 市场敏感度非常高。

一些学者也探讨用各种货币供应量来分析政府 信用风险。我国的货币供应量是以 M0、M1、M2为框 架体系。与消费变动密切相关且最活跃的货币供应 量是现金, 称为 $\mathrm{M} 0$ 。 M0 与非金融性公司的活期存款 之和为 $\mathrm{M} 1$, 它反映了社会的直接购买能力。 $\mathrm{M} 2=\mathrm{M} 1+$ 非金融性公司的定期存款+储蓄存款 + 其他存款, M2 反映了现实的购买力, 也反映了潜在的购买力。

其实, 政府并不发放货币, 政府是为央行发行 的货币提供信用担保。货币供应量过大, 必然引起 通货膨胀率, 政府信用降低。为了给过多的货币寻 找出路, 虚拟经济常常受到政府的鼓励, 认为资本 市场的发展、金融创新的加速, 使货币流通速度不 断变化, 从而货币供应量与通货膨胀短期和中期的 关系减弱。

用通胀对政府信用风险进行量化分析的主要困 难是通胀指数常常被操纵。CPI可能反映不了真实的 通胀是最好的例证。有研究认为, M0、M1和M2口径 的货币供应量对我国的通货膨胀均没有影响 ${ }^{8}$; 但也 有研究认为, M2 与通货膨胀之间存在长期均衡关系 。从从货币交易方程推导出来用于测度通货膨胀压力 
的P-Star模型 ${ }^{10}$, 历经二十多年的发展, 目前仍停留 在研究阶段。

\section{6. 三元信用风险的研究方法}

本文提出的三元信用风险 $\varphi_{x}(y, z)$, 远比任何的 二元风险 $\varphi_{x}(y)$ 复杂。原则上来讲, 用演绎推理或统 计学习总是可以构建出二元风险的分析模型, 但难 以构建三元分析模型。原因是演绎推理中很难处理 两个自变量之间的相互影响, 而统计学习的样本基 本无从获取。

从理论上讲, 研究三元信用风险, 只能从社会 经济动力学入手, 由构造微分方程起步, 用各种约 束简化问题。从实用的角度讲, 将自变量区分为主 自变量和从自变量, 则多态灾害链模型 ${ }^{11}$ 可发展为 三元信用风险分析模型。我们以 “民众承担的信用 风险”为例来加以说明。

从概率风险的角度看, 一个风险现象的形式化 描述就是不利事件发生的概率 $P$ 和后果 $V$ 。特别 地, 当我们假定它们与某个参数 $y$ 有关时, 风险分 析的主要工作就是识别概率分布 $p(\mathrm{y})$ 和脆弱曲线 $v(\mathrm{y})$ 。当风险的内涵是破坏的期望值时, 风险值为

$$
R=\int_{0}^{\infty} p(y) v(y) d y
$$

例如, 假定政府的信用完全由通胀率 $y$ 决定, 又假定民众因 $y$ 成的财富蒸发是 $v(y)$ 。当 $y$ 在研究时 期内的概率分布是 $p(y)$ 时, 风险值由式 (6) 算出。

分析三元信用风险的困难在于, 民众财富的蒸 发不仅受政府信用的影响, 而且可能受银行破产的 影响。高通胀不仅使财富蒸发, 还会使企业破产造 成大量失业。在将自变量区分为主自变量和从自变 量后, 三元信用风险分析的问题就被大大简化。

在某些国家, 高通胀刺激房货, 银行潜在风险 增加, 上市银行的股民除承受政府信用风险外又承 受银行股价下跌的风险。外观上看, 如果能分别计 算出财富蒸发的期望值和股价下跌造成损失的期望 值, 两者相加则是民众承受的风险。问题是, 通胀 率和银行信用并不独立, 简单的相加可能严重失 真。

将多态灾害链模型发展为多态风险分析模型, 关键是找出一个链结构, 通过用各风险环的研究, 分析出民众承担的信用风险。

在多态灾害链中, 我们用 $M, O, D, L$ 分别表示致 灾因子、承灾体、破坏、损失参数（或矢量）, 用 $P(L)$ 表示损失 $L$ 的概率值。一个灾害环的形式化描 述是:

$$
\left\{\begin{array}{l}
P(L)=S(D, M) \\
D=F(M, O)
\end{array}\right.
$$

式中, 函数 $F$ 的形式和参数由承灾体所处环境和承 灾体类型决定; 函数 $S$ 的形式和参数由承灾体社会 属性和致灾因子 $M$ 的不确定性属性决定。

如果有灾害链存在, 则破坏 $D$ 将诱导出新的致 灾因子, 记为 $M_{1}=\Phi(D)$ 。例如, 地震引起山崩, 山崩形成拦河大坝, 大坝溃决造成洪水灾难。山崩 是破坏 $D$, 洪水是由地震诱导出的致灾因子 $M_{1}$ 。诱 导关系 $\Phi$, 可能非常复杂, 也可能十分简单。

显然, 不失一般性, 在三元信用风险 $\varphi_{x}(y, z)$ 中, 我们可以假定 $y$ 是主自变量, $z$ 是从自变量, 并 假定 $z$ 由 $\mathrm{y}$ 诱导, 且 $y$ 在发展的过程中有足够的时 间允许人类对其加以影响。与放任不管的形态相 比, 可能会有另外的形态出现。这样, 系统风险就 会出现多态性, 本文称其为多态风险链。

设 $x$ 承担由于主自变量 $y$ 之信用不良产生的信 用风险为 $\varphi_{x}(y)$, 从自变量 $z$ 由 $\mathrm{y}$ 诱导的关系式为 $\Phi(y, z)=0$, 则一个风险环的形式化描述是:

$$
\left\{\begin{array}{l}
R=\varphi_{x}(y) \\
\Phi(y, z)=0
\end{array}\right.
$$

由于 $x$ 承担从自变量 $z$ 之信用不良产生的信用 风险可记为 $\varphi_{x}(z)$, 于是, 由 $\mathrm{y}$ 诱导的风险环是

$$
\left\{\begin{array}{l}
R_{1}=\varphi_{x}(z) \\
\Phi(y, z)=0
\end{array}\right.
$$

当有 $n$ 个手段可对 $y$ 的发展过程加以影响时, $\mathrm{y}$ 的诱导形式和结果都会有所不同, 这些诱导式可分 别记为 $\Phi_{1}, \cdots, \Phi_{n}$ 。于是, 一个多态风险分析模型 可表为:

$$
\left\{\begin{array}{c}
R=\varphi_{x}(y) \\
\Phi(y, z)=0
\end{array},\left\{\begin{array}{c}
\left\{\begin{array}{c}
R_{1}=\varphi_{x}(z) \\
\Phi_{1}(y, z)=0 \\
\vdots
\end{array}\right. \\
\left\{\begin{array}{c}
R_{1}=\varphi_{x}(z) \\
\Phi_{n}(y, z)=0
\end{array}\right.
\end{array}\right.\right.
$$

在 $y$ 失信前, 人们并不知道什么样的影响手段 将会被采用。于是, 分析三元信用风险, 必须考虑 概率分布 $P\left(\Phi_{1}\right), P\left(\Phi_{2}\right), \cdots, P\left(\Phi_{n}\right)$ 。这显然不是一件 容易的工作。

\section{7. 用智联网改善信用风险识别}

信用风险的分析工作是一项智能工作。如何发 挥互联网的作用, 集众人之所长, 生超级之智能, 解风险之万千, 是一个值得研究的问题。

面对一个具体的信用风险问题, 目前普遍依赖 利益相关者自己的经验和各种途径得来的专家指导 
去应对。但是, 世界越来越复杂, 大数据时代已经 到来, 各种风险瞬息万变。无论多复杂的信用风险 分析工具, 无论多大的数据库, 都会越来越难以满 足需要。借助互联网强大的功能, 集百家之智, 历 万家之险, 解动态之迷, 才有可能大大提高人们应 对信用风险的能力, 使复杂变简单, 不变应万变。

基于人类智慧远远高于机器智能而互联网能集 成高级智慧的认识, 文 12 首次提出 “智联网”的概 念, 它由智能体、互联网和一个数学模型构成, 以 汇集和处理相关信息, 有望提高人们对各种风险的 分析能力。为此, 本文提出用智联网改善风险识别 的方略。

\section{1. 智联网概念}

“智联网”(Internet of Intelligences), 是由各种智 能体, 通过互联网形成的一个巨大网络。其目的是 集小智慧为大智慧, 群策群力, 帮助人们更好地认 识世界, 获得更好的生活质量。

设 $A=\left\{a_{1}, a_{2}, \ldots, a_{n}\right\}$ 是含有 $n$ 个智能体 $a_{1}, a_{2}, \ldots, a_{n}$ 的一个集合。设 $N=\left\{S, c_{1}, c_{2}, \ldots, c_{n}\right\}$ 是含有服务器 $S$ 和 $n$ 台计算机网络终端 $c_{1}, c_{2}, \ldots, c_{n}$ 的, 一个可以独立工 作的子系统。设 $M$ 是处理 $n$ 个智能体所提供的信息 的模型。三元体 $(A, N, M)$ 称为一个智联网。

设 $(A, N, M)$ 是一个智联网, 智力水平为 $Q$ 。 再设 $A$ 中个体的最大智力水平为 $q$ 。当 $Q$ 大于 $q$ 时, 称 $(A, N, M)$ 为一个正向智联网。智联网是一 个智力提升系统, 只有正向智联网才有意义。简单 的网络调查系统不是智联网。

最早的计算机网络于 1969 年正式启用, 由美国 军事部门 ARPA 研制, 称为 ARPAnet, 仅连接了 4 台计算机。1974 年, 人们开发了 TCP/IP 协议, 继而 产生了世界上第一个网页浏览器和第一个网页服务 器, 人类进入互联网时代。随后搭建的网络高速公 路, 实现了组织机构间的联网, 电子商务应运而 生。这个时期的网页模式可称为 Web 1.0。

在二十世纪 90 年代, 人与人之间的联网得以实 现，产生了个体对他人跨界响应的 “社会技术”， 名目繁多的网络社区层出不穷。这个时期网络界面 的模式可称为 Web 2.0。

网络技术的飞速发展, 为人们从网络虚拟空间 走向网络实体空间创造了条件, 并刺激人们用算法 从网页中提取信息。于是物联网应运而生, 语义网 呼之欲出。帮助人们在任何时间、任何地点、以任 何方式进行信息的获取与处理的普适计算, 成为今 天的研究热点, 云计算等正在普及。这种建设中的 网络被称为 Web 3.0。

然而, 无论是千奇百怪的单体计算机还是纵横 全球的计算机网络系统, 虽然能较好地处理事务性
和计算性的工作, 但不能处理未知情况, 难以适应 快速变化的环境, 无法进行创造性的工作。所以, 现在能够完成复杂任务的网络, 只不过速度更快、 数据更多, 花样更新, 但其智力还不如 3 岁的小 孩。

未来的网络系统, 是智与智之间联网, 这就是 智联网。为构建正向智联网而开展的增强思维之理 论和方法的研究, 内涵丰富, 挑战无限。这种未来 的网络, 基本模式可称为 Web 4.0。图 1 总结了从 Web 1.0 到 Web 4.0 的发展历程。

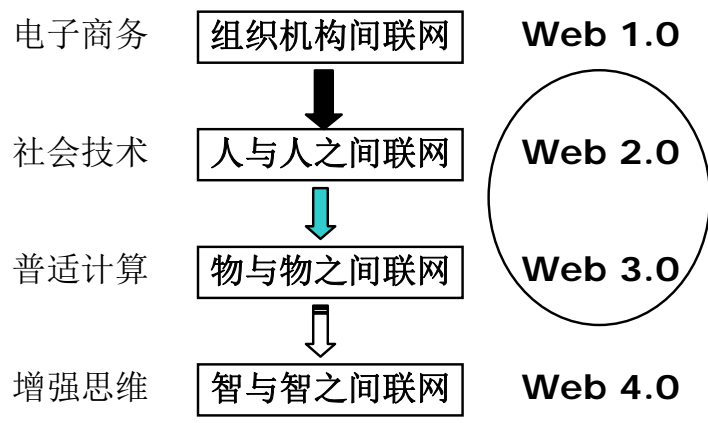

图 1. Web 1.0 到 Web 4.0 的发展历程

由图 1 可知, 互联网发展的必然趋势是智联 网。今天我们处于从 Web 2.0 向 Web 3.0 发展的过 程中。

\section{2. 用智联网改善风险识别的方略}

征信系统大量投入商业应用说明, 银行对普通 客户信用风险的识别, 技术上已无障碍, 只剩精度 和成本问题。然而, 对涉及新兴产业市场的客户, 征信系统可能失效。更一般地, 一旦政治、经济和 社会环境等的变化较大, 基于客户历史信用记录的 传统风险识别技术就会失效。商业银行风险和政府 信用风险, 相当隐蔽且变化多端, 不仅个体民众很 难对其加以识别, 评估机构也常常误判。三元信用 风险，更为复杂，目前尚无有效识别技术。

对此, 智联网有两个应对方略: 直接识别和间 接感受。

I. 直接识别法

设 $O$ 的信用风险是待识别对象。传统的识别方 法是将 $O$ 的属性数据放入某种模型, 经分析而辩识 出风险的大小。与利益相关者的关系数据、抗压能 力等也可在属性数据之列。用什么样的属性数据, 由所谓的风险评估指标体系确定。

用智联网对 $O$ 的信用风险进行识别, 依据的是 网上智能体对问题的认识, 而非对属性数据的群体 分析。 
当 $O$ 的信用风险与公众生活密切相关且有大量 公开资料时, 可用智联网对其加以直接识别。例 如, 某大企业 $O$ 拟生产一种全新的日用品, 其巨额 贷款的信用风险, 不仅与征信系统中以往 $O$ 的属性 数据有关, 还与消费者现今对 $O$ 的认可程度和该新 产品的市场有关。用智联网直接对 $O$ 的认可程度和 新产品进行评价, 并辅之以对以往信用的分析, 就 可以识别出对此项贷款的信用风险。

此时, 商业银行由智联网发布的问题形式是: 对 $O$ 的认可程度如何? 消费此产品的愿望如何? 并 要求给出理由。智联网 $(A, N, M)$ 中的模型 $M$, 首 选拼图模式。

任何智联网都是一个交易平台。银行使用智联 网对大客户进行信用风险识别, 须有相应的投入, 大部分支付给有效应答的智能体集合 $A$ 。由于智联 网具有过滤虚假信息和处理不完备信息的能力, 其 投入产出将会远远高于传统的征信系统。

\section{II. 间接感受法}

许多信用风险不可计算, 只可感受。例如, 2012 年欧洲债务危机, 不可避免地会影响到政府信 用和银行信用, 但其风险难以计算, 只可感受。对 于大型项目的投资者而言, 识别出这类信用风险, 有利于科学决策。如果政府信用风险过大, 社会可 能不稳, 自有资金不宜投入; 如果银行信用风险过 大，计划中的贷款会有变故。

显然，任何投资者都无力针对政府或银行建立 征信系统, 只有从媒体信息才能感受相关风险。由 于不同环境下的语义差别很大, 现有网页提取的信 息不能用于风险识别。

当人们无休止地争论用什么样的标准来建设语 义网, 便于机器识别和理解时, 智联网跳过了这障 碍, 用工具箱模式解决了这问题。当人们大力开发 生物算法以图实现计算智能时, 智联网直接使用人 的智能而简化过程。当人们热情不减地进行词语计 算的研究, 以图用网页上的词语进行推理时, 智能 体天生的词语处理能力正被智联网的各种模式所使 用。

于是, 用智联网间接感受, 并辅之以必要的统 计分析, 就可以识别出难以计算但涉及公共利益的 信用风险。

以项目投资者对政府信用的间接感受而言, 其 由智联网发布的问题形式, 可类似于: 非你个人原 因的生活压力近期是否会有缓解? 给出判断的理 由。如果压力进一步增大, 三年后的极端情况会是 什么? 并要求给出理由。智联网 $(A, N, M)$ 中的模 型 $M$, 首选路况模式。

\section{8. 结论}

金融风险防范的基础工作之一是信用风险识 别。以往人们过多关注微观层次的信用风险, 大量 征信系统投入应用。宏观性较强的银行和政府信用 风险, 正在引起人们的关注。

由银行、政府和民众组成的系统中, 存在 6 类 信用风险：客户信用风险、银行信用风险、政府信 用风险、民众承担的信用风险、银行承担的信用风 险和政府承担的信用风险。前 3 类是二元的信用风 险, 后 3 类是三元的信用风险。

传统上, 客户信用风险主要是根据属性数据进 行识别。巴塞尔资本协议推荐使用的方法有助于对 银行信用风险进行识别。主权信用评级可作为政府 信用风险的一项重要指标。三元信用风险的识别因 两个自变量的关联而相当复杂。多态风险分析模型 可略为简化问题。

由智能体集合、计算机网络和信息处理模型组 成的智联网, 由于具有动态跟踪和提升智能的能 力, 十分有助于改善信用风险的识别。直接识别方 略和间接感受方略都可以将传统的静态模式推进到 动态, 提供风险识别的准确度。

由于受与 “北京崇安智联科技服务有限责任公 司” 签订的保密协议约束, 智联网中的相关技术, 无法在本文加以介绍。

\section{参考文献}

1. Gu Qianping, Research of Credit Risk Model for Companies in Commercial Banks, Dissertation for the doctoral degree in Tsing-hua University Tsing-hua University, (2009).

顾乾屏, 商业银行法人客户信用风险模型研究, 清华大 学经济管理学院博士学位论文, 清华大学, (2009)

2. E. Altman, Financial ratios: Discriminant analysis and the prediction of corporate bankruptcy. The Journal of Finance. (23) (1968): 589-609.

3. Wei Yutao, Emphasis on legal risks of local financing platform, China Economic Times, 2012.11.30, third version.

魏域涛, 重视地方融资平台的法律风险, 中国经济时报, 2012 年 11 月 30 日, 第 003 版.

4. Wu Wei, Ai Junwei, Risk management research of local government investment and financing platform Foreign and Economic Relations \& Trade, (3) (2012): 57-59.

吴蔚, 艾军卫, 地方政府投融资平台风险管理研究, 对 外经贸, (3) (2012): 57-59.

5. Basel Committee on Banking Supervision. Sound Practices for the Management and Supervision of Operational Risk. (Basel, Switzerland, Bank for International Settlements, 2003).

6. Basel Committee on Banking Supervision. International Convergence of Capital Measure-ment and Capital Standards: A Revised Framework. (Basel, Switzerland, Bank for International Settle-ments, 2004). 
7. Hu Weiming, Sovereign credit rating model of Moody and its Enlightenment, China finance, (9) (2012): 78-80. 胡伟民, 穆迪主权信用评级模式及其启示, 中国金融, (9) (2012): 78-80.

8. Chen Yanbin, Tang Shilei, Li Du. Can Money Supply Forecast Inflation in China? Economic Theory and Business Management, V(2) (2009): 22-28.

陈彦斌, 唐诗否, 李杜, 货币供应量能预测中国通货膨 胀吗? 经济理论与经济管理, V(2) (2009): 22-28.

9. Yang Jianming, China's money supply empirical research on output, price forecasting ability, Naikai Economic studies, (1) (2003).

杨建明, 我国货币供应量对产出、物价预测能力的实 证研究, 南开经济研究, (1) (2003).

10. J. J. Hallman, R. D. Porter and D. H. Small, M2 per Unit of Potential GNP as an Anchor for the Price Level. Staff Studies, No.157, Board of Governors of the Federal Reserve System, 1989

11. Huang Chongfu, Status of comprehensive risk management framework for design and multi-state,disaster, Journal of Basic Science and Engineering, 14(sup) (2006): 29-37.

黄崇福, 综合风险管理的地位、框架设计和多态灾害 链风险分析研究, 应用基础与工程科学学报, 14(增刊) (2006): 29-37.

12. 黄崇福. 风险分析在线服务的智联网. Journal of Risk Analysis and Crisis Response, 1(2) (2011): 110-117. 